\title{
Seleno L-Methionine Acts on Cyclophosphamide-Induced Kidney Toxicity
}

\author{
Adnan Ayhanci • Sibel Günes • Varol Sahinturk • \\ Sila Appak • Ruhi Uyar • Mustafa Cengiz • \\ Yilmaz Altuner • Suzan Yaman
}

Received: 29 August 2009 / Accepted: 23 September 2009 /

Published online: 14 October 2009

(C) Humana Press Inc. 2009

\begin{abstract}
The anticancer drug cyclophosphamide (CP) has nephrotoxic effects besides its urotoxicity, which both in turn limit its clinical utility. The nephrotoxicity of CP is less common compared to its urotoxicity, and not much importance has been given for the study of mechanism of CP-induced nephrotoxicity so far. Overproduction of reactive oxygen species (ROS) during inflammation is one of the reasons of the kidney injury. Selenoproteins play crucial roles in regulating ROS and redox status in nearly all tissues; therefore, in this study, the nephrotoxicity of $\mathrm{CP}$ and the possible protective effects of seleno L-methionine (SLM) on rat kidneys were investigated. Forty-two Sprague-Dawley rats were equally divided into six groups of seven rats each. The control group received saline, and other rats were injected with CP (100 mg/kg), SLM (0.5 or $1 \mathrm{mg} / \mathrm{kg})$, or CP+ SLM intraperitoneally. Malondialdehyde (MDA) and glutathione (GSH) levels in kidney homogenates of rats were measured, and kidney tissues were examined under the microscope. CP-treated rats showed a depletion of renal GSH levels ( $28 \%$ of control), while $\mathrm{CP}+\mathrm{SLM}$-injected rats had GSH values close to the control group. MDA levels increased $36 \%$ of control following CP administration, which were significantly decreased after SLM treatment. Furthermore, these biochemical results were supported by microscopical observations. In conclusion, the present study not only points to the therapeutic potential of SLM in CP-induced kidney toxicity but also indicates a significant role for ROS and their relation to kidney dysfunction.
\end{abstract}

\footnotetext{
A. Ayhanci $(\bowtie) \cdot S$. Günes $\cdot$ M. Cengiz $\cdot$ Y. Altuner $\cdot$ S. Yaman

Faculty of Arts and Science Department of Biology, Eskisehir Osmangazi University,

Meselik Campus F5, 26480 Eskisehir, Turkey

e-mail: aayhanci@ogu.edu.tr

V. Sahinturk

Faculty of Medicine Department of Histology, Eskisehir Osmangazi University, Eskisehir, Turkey

S. Appak

Department of Molecular Biology \& Genetics, Izmir Institute of Technology, Izmir, Turkey

R. Uyar

Faculty of Medicine Department of Physiology, Eskisehir Osmangazi University, Eskisehir, Turkey
} 
Keywords Seleno L-methionine $\cdot$ Cyclophosphamide $\cdot$ Nephrotoxicity $\cdot$ Cytoprotectivity $\cdot$ Kidney $\cdot$ Rat

\section{Introduction}

Cyclophosphamide (CP) is a drug with a wide spectrum of clinical uses, and it has been proved to be effective in the treatment of cancer (lymphoma, acute and chronic leukemias, and multiple myeloma) and non-malignant disease states such as rheumatoid arthritis [1]. However, this drug may induce acute inflammation in the urinary bladder (cystitis) and causes renal damage [2,3] and liver damage [4], thereby limiting its therapeutic window. Ifosfamide and CP have to be activated through a metabolic step in vivo in which numerous metabolites are known [5]. Studies have shown that CP can also cause nephrotoxicity besides its urotoxic effects $[3,4]$. The nephrotoxicity of $\mathrm{CP}$ was generally overlooked because plasma creatinine, an indicator of glomerular function of the kidney, is not altered significantly in patients on CP chemotherapy. However, in a recent study, Sugumar et al. [6] have demonstrated in a rat model that $\mathrm{CP}$ induces renal damage microscopically but a reliable biochemical marker of renal dysfunction, the plasma creatinine, remained unaltered. $\mathrm{CP}$ can result in glomerular dysfunction and tubular dysfunction [6, 7]. The nephrotoxicity is considered to be dose dependant and includes a variable reduction of glomerular filtration rate along with tubular dysfunction.

Phosphoramide mustard (PAM) and acrolein (ACR) are two active metabolites of cyclophosphamide produced by the liver microsomal enzymes [8]. Cyclophosphamide's antineoplastic effects are associated with PAM, while ACR is linked with its toxic side effects. ACR interferes with the tissue antioxidant defense system [9], produces highly reactive oxygen-free radicals [10], and are mutagenic to mammalian cells [11]. Antioxidant agents like amifostine, a thiol antioxidant, have cytoprotective action against platinuminduced renal toxicity. However, amifostine is not used due to its toxic effects: hypocalcaemia, anxiety, and hypotension [12].

Seleno L-methionine is a nutritionally essential trace element representing the major nutritional source of selenium for higher animals and humans [13]. Se is a constituent of glutathione peroxidase (GSH-Px), an enzyme that uses glutathione (GSH) to remove hydrogen peroxide as well as fatty acid hydroperoxides, thereby preventing hydroxyl radical formation [14]. The level of MDA, a marker of lipid peroxidation, was found to be higher in tumor than in non-tumor tissues [15]. Selenium was found to be highly protective against toxicity induced by a variety of chemotherapeutic agents [16]. The aim of the present study was to investigate the potential protective effects of pharmacological dosages of seleno L-methionine against CP-induced kidney damage in rats.

\section{Materials and Methods}

Chemicals and Drugs

CP (Endoxan, Cyclophosphamide Monohydrate, C0768) was purchased from SigmaAldrich, Taufkirchen, Germany. Se (Seleno-L-Methionine, S3132) was purchased from Sigma, Germany. 
Experimental Protocol

A total of 42 Sprague-Dawley rats of either sex, $200 \pm 20 \mathrm{~g}$, were provided by the Experimental Animal Research Facility, Eskisehir Osmangazi University, Eskisehir, Turkey. The rats were housed under conditions of controlled temperature $\left(22^{\circ} \mathrm{C}\right)$ and acclimatized to 12:12 h light/dark cycle. Animals were given food and water ad libitium. Animal experiments were conducted according to the guidelines of Institutional Animal Ethics Committee (DateProtocol no: 16.06.2009-117/2009).

The rats were randomly divided into the following experimental groups, each including seven animals: Group 1 served as the vehicle (normal saline) treated controls. Group 2 animals received CP i.p. dissolved in saline, in a single dose of $100 \mathrm{mg} / \mathrm{kg}$ b.w. Groups 3 and 4 were treated with 0.5 or $1 \mathrm{mg} / \mathrm{kg}$ seleno L-methionine (SLM) for six consecutive days. The animals of group 5 or 6 received respective SLM for 6 days and then a single dose of CP administered on the fourth day [17]. Animal groups and their treatments are summarized in Table 1.

\section{Sample Collection and Biochemical Assays}

All animals were anesthetized with an i.p. injection of $60 \mathrm{mg}$ sodium pentobarbitone per kilogram of b.w. and then killed by cervical dislocation $24 \mathrm{~h}$ after the final saline, CP, or SLM injections. The kidneys were removed intact, washed with saline, and blotted dry on a filter paper. The kidneys were then cut into two equal pieces. One half was stored at $-20^{\circ} \mathrm{C}$ to measure kidney MDA and GSH contents; the rest was fixed for $24 \mathrm{~h}$ in $10 \%$ buffered formaldehyde (Table 2).

Histological Procedures

For light microscopy, tissues were processed routinely for paraffin embedding, and 5- $\mu \mathrm{m}$ serial cross sections were stained and examined for the presence of necrosis, edema,

Table 1 Groups of Rats $(n=7)$ and Their Treatments

\begin{tabular}{|c|c|c|c|c|c|c|c|}
\hline \multirow[t]{2}{*}{ Groups } & \multicolumn{7}{|l|}{ Days } \\
\hline & 1 & 2 & 3 & 4 & 5 & 6 & 7 \\
\hline Control & Saline & Saline & Saline & Saline & Saline & Saline & $\mathrm{X}$ \\
\hline $\mathrm{CP}$ & Saline & Saline & Saline & $\mathrm{CP}$ & Saline & Saline & $\mathrm{X}$ \\
\hline 0.5 SLM & $\begin{array}{l}\text { SLM } \\
(0.5 \mathrm{mg} / \mathrm{kg})\end{array}$ & $\begin{array}{l}\text { SLM } \\
(0.5 \mathrm{mg} / \mathrm{kg})\end{array}$ & $\begin{array}{l}\text { SLM } \\
(0.5 \mathrm{mg} / \mathrm{kg})\end{array}$ & $\begin{array}{l}\text { SLM } \\
(0.5 \mathrm{mg} / \mathrm{kg})\end{array}$ & $\begin{array}{l}\text { SLM } \\
(0.5 \mathrm{mg} / \mathrm{kg})\end{array}$ & $\begin{array}{l}\text { SLM } \\
(0.5 \mathrm{mg} / \mathrm{kg})\end{array}$ & $\mathrm{X}$ \\
\hline 1 SLM & $\begin{array}{l}\text { SLM } \\
\qquad(1 \mathrm{mg} / \mathrm{kg})\end{array}$ & $\begin{array}{l}\text { SLM } \\
\qquad(1 \mathrm{mg} / \mathrm{kg})\end{array}$ & $\begin{array}{l}\text { SLM } \\
\qquad(1 \mathrm{mg} / \mathrm{kg})\end{array}$ & SLM (1 mg/kg) & $\begin{array}{l}\text { SLM } \\
\qquad(1 \mathrm{mg} / \mathrm{kg})\end{array}$ & $\begin{array}{l}\text { SLM } \\
\qquad(1 \mathrm{mg} / \mathrm{kg})\end{array}$ & $\mathrm{X}$ \\
\hline $\begin{array}{l}\text { CP+0.5 } \\
\text { SLM }\end{array}$ & $\begin{array}{l}\text { SLM } \\
(0.5 \mathrm{mg} / \mathrm{kg})\end{array}$ & $\begin{array}{l}\text { SLM } \\
(0.5 \mathrm{mg} / \mathrm{kg})\end{array}$ & $\begin{array}{l}\text { SLM } \\
(0.5 \mathrm{mg} / \mathrm{kg})\end{array}$ & $\begin{array}{l}\text { SLM } \\
(0.5 \mathrm{mg} / \mathrm{kg}) \\
+\mathrm{CP}\end{array}$ & $\begin{array}{l}\text { SLM } \\
(0.5 \mathrm{mg} / \mathrm{kg})\end{array}$ & $\begin{array}{l}\text { SLM } \\
(0.5 \mathrm{mg} / \mathrm{kg})\end{array}$ & $\mathrm{X}$ \\
\hline $\begin{array}{r}\mathrm{CP}+1 \\
\mathrm{SLM}\end{array}$ & $\begin{array}{l}\text { SLM } \\
\qquad(1 \mathrm{mg} / \mathrm{kg})\end{array}$ & $\begin{array}{l}\text { SLM } \\
(1 \mathrm{mg} / \mathrm{kg})\end{array}$ & $\begin{array}{l}\text { SLM } \\
\qquad(1 \mathrm{mg} / \mathrm{kg})\end{array}$ & $\begin{array}{l}\text { SLM }(1 \mathrm{mg} / \mathrm{kg}) \\
\quad+\mathrm{CP}\end{array}$ & $\begin{array}{l}\text { SLM } \\
(1 \mathrm{mg} / \mathrm{kg})\end{array}$ & $\begin{array}{l}\text { SLM } \\
\qquad(1 \mathrm{mg} / \mathrm{kg})\end{array}$ & $\mathrm{X}$ \\
\hline
\end{tabular}

$C P$ cyclophosphamide (100 mg/kg), SLM seleno L-methionine, $X$ killed 
Table 2 MDA and GSH Levels in Kidney Tissue of Rats Treated with CP, SLM, and SLM Followed by CP

\begin{tabular}{lcc}
\hline Groups $(n=7)$ & MDA $(\mathrm{nmol} / \mathrm{g}$ protein) & GSH $(\mu \mathrm{mol} / \mathrm{g}$ protein) \\
\hline Control & $14.22 \pm 1.36$ & $38.20 \pm 1.66$ \\
CP & $22.17 \pm 1.25^{\mathrm{a}}$ & $27.79 \pm 0.97^{\mathrm{a}}$ \\
$0.5 \mathrm{SLM}$ & $14.35 \pm 0.93^{\mathrm{b}, \mathrm{c}}$ & $40.81 \pm 2.14^{\mathrm{a}, \mathrm{b}, \mathrm{c}}$ \\
1SLM & $14.81 \pm 0.79^{\mathrm{b}, \mathrm{d}}$ & $41.14 \pm 1.36^{\mathrm{a}, \mathrm{b}, \mathrm{d}}$ \\
CP+0.5SLM & $17.36 \pm 1.13^{\mathrm{a}, \mathrm{b}}$ & $36.86 \pm 0.88^{\mathrm{b}}$ \\
CP+1SLM & $19.37 \pm 0.96^{\mathrm{a}, \mathrm{b}, \mathrm{c}}$ & $36.87 \pm 1.12^{\mathrm{b}}$ \\
\hline
\end{tabular}

Values are shown as mean $\pm \mathrm{SD}$

${ }^{\text {a }}$ Significantly different from controls $(p<0.05)$

${ }^{\mathrm{b}}$ Significantly different from CP group $(p<0.05)$

${ }^{\mathrm{c}}$ Significantly different from CP+0.5 SLM group $(p<0.05)$

${ }^{\mathrm{d}}$ Significantly different from CP+1 SLM group $(p<0.05)$

hemorrhage, tubular degeneration, mononuclear/polimorphonuclear cell infiltration, and narrowing of Bowman's capsule space [18].

Malondialdehyde

MDA content was measured as described by Ohkawa et al. in 1979 [19]. Kidney tissues were homogenized in appropriate buffers and used for the following assays. The mixture consisted of $0.8 \mathrm{ml}$ of sample $(1 \mathrm{mg}), 0.2 \mathrm{ml}$ of $8.1 \%$ sodium dodecylsulfate, $1.5 \mathrm{ml}$ of $20 \%$ glacial acetic acid adjusted to $\mathrm{pH}=3.5$, and $1.5 \mathrm{ml}$ of $0.8 \%$ aqueous solution of thiobarbituric acid. The mixture was diluted to $4 \mathrm{ml}$ with distilled water and heated at $95^{\circ} \mathrm{C}$ for 60 . Distilled water $(1 \mathrm{ml})$ and $5 \mathrm{ml} n$-butanol and pyridine mixture (15:1) were added and centrifuged at $2,000 \times \mathrm{g}$ for $10 \mathrm{~min}$. The absorbance of the organic layer was measured at $532 \mathrm{~nm}$. Amount of thiobarbituric reacting substances formed is calculated from standard curve prepared using 1, 1', 3, 3' tetramethoxy propane, and the values were expressed as nmol MDA/g tissue.

\section{Glutathione}

Tissue levels of acid-soluble thiols, mainly GSH, were determined colourimetrically at $412 \mathrm{~nm}$. Briefly, $0.5 \mathrm{ml}$ of the previously prepared homogenate was added to $0.5 \mathrm{ml}$ of $5 \%$ trichloroacetic acid, and after centrifugation at $750 \times \mathrm{g}$ for $5 \mathrm{~min}$, the supernatant $(200 \mu \mathrm{l})$ was added to a tube containing $1,750 \mu \mathrm{l}$ of $0.1 \mathrm{~mol} / 1$ potassium phosphate buffer, $\mathrm{pH}=8$, and $50 \mu 1$ 5,5'-dithiobis-(2-nitrobenzoic acid) reagent. Tubes were mixed, and the yellow color that developed was measured against a standard curve of GSH. The protein thiol (protein-SH) content was expressed as $\mu \mathrm{mol} / \mathrm{g}$ of tissue.

\section{Statistics}

The results were expressed as means \pm SD and $p<0.05$ accepted as statistically significant. Statistical analyses were performed using one-way analysis of variance for MDA and GSH levels. The Tukey's test was then performed to analyze the two groups consecutively. 


\section{Results}

\section{Biochemical Results}

CP significantly increased MDA relative to the control $(36 \%, p<0.05)$, which was significantly restored in the kidneys of the animals pretreated with SLM $(0.5$ or $1 \mathrm{mg} / \mathrm{kg} / \mathrm{day})$ as opposed to those receiving only CP tissue (see Fig. 1). CP also produced a significant reduction in GSH $(28 \%)$ of the kidney relative to the control $(p<0.05)$. Groups receiving SLM $(0.5$ or $1 \mathrm{mg} / \mathrm{kg} /$ day $)$ showed a significant restoration in GSH concentration of the kidney. The group of rats having SLM alone showed no significant alteration in the levels of MDA and GSH (see Fig. 2).

\section{Microscopic Evaluation}

Microscopical observations also provided supportive evidence for the biochemical results as seen in Fig. 3. Medullar regions showed normal histology in all sections of the groups. The kidneys of the control and the groups having SLM alone showed normal histology. Kidney tissues of CP-administered rats showed desquamation of tubular epithelial cells with accumulation of eosinophilic granular material within the lumen of the tubules and narrowing of Bowman's capsule spaces. In the CP+SLM groups, SLM decreased the degeneration of the tubules and the kidney corpuscles looked normal.

\section{Discussion}

$\mathrm{CP}$ has been associated with various kinds of urinary tract toxicities [20,21], but kidney toxicity has only rarely been reported. In 1961, Philips et al. reported that renal papillary

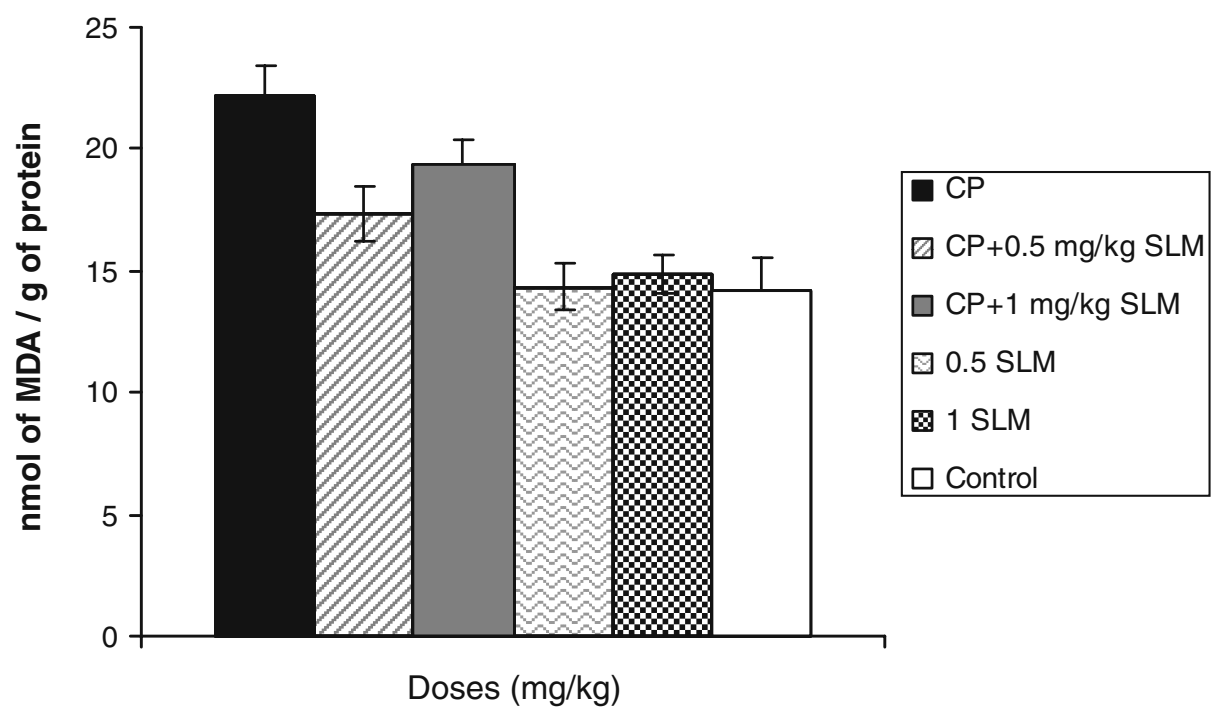

Fig. 1 MDA levels of the kidney. CP administration significantly increased MDA level relative to the control (36\%), which was significantly restored kidney in animals pretreated with SLM (0.5 or $1 \mathrm{mg} / \mathrm{kg} / \mathrm{day})$ as opposed to those receiving only CP tissue $(p<0.05)$ 


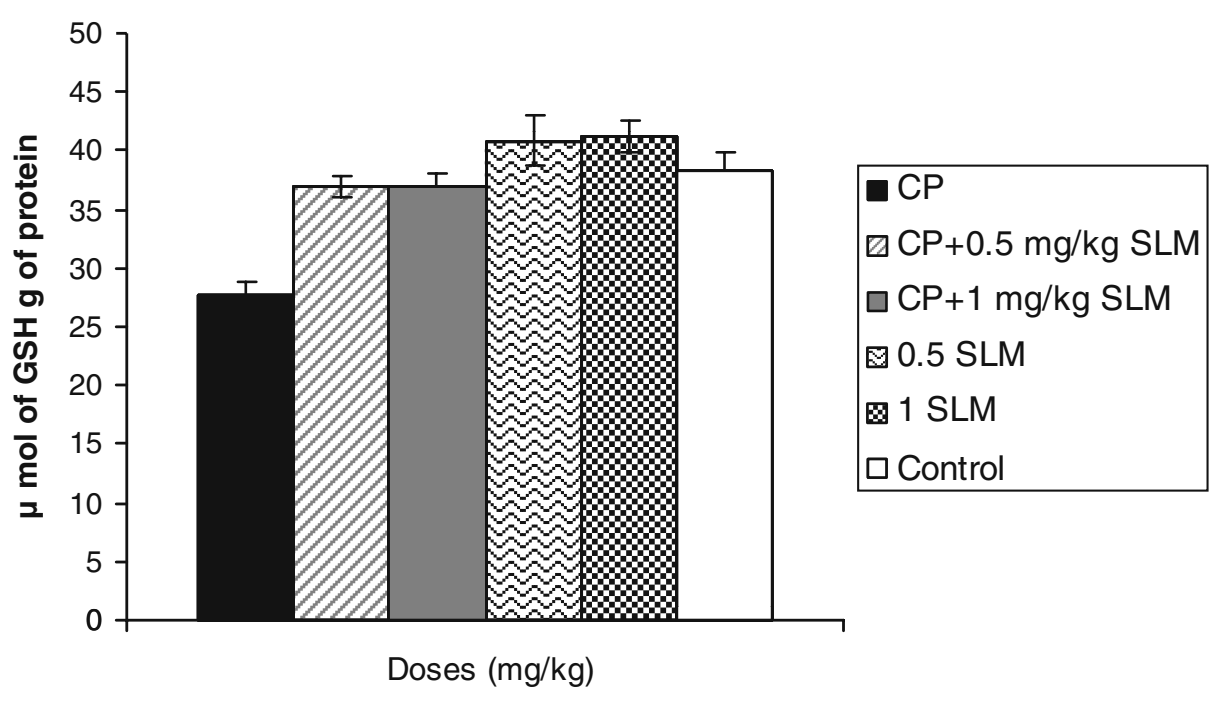

Fig. 2 CP produced a significant reduction in GSH level $(28 \%)$ in the kidney relative to the control $(p<0.05)$. Groups receiving SLM (0.5 or $1 \mathrm{mg} / \mathrm{kg}$ /day) showed a significant restoration in GSH concentration in the kidney $(p<0.05)$

necrosis had developed after a single i.p. injection of CP $(222 \mathrm{mg} / \mathrm{kg})$ in male rats [22]. Since then, there have been a few publications concerning the nephrotoxicity of $\mathrm{CP}$ in animal experiments, but these have only mentioned renal tubular necrosis [23] or glomerular changes [24].

In the present study, it was shown that treatment with only $\mathrm{CP}$ caused nephrotoxicity in rats, as evidenced by the high biochemical parameters such as high lipid peroxidation (MDA) and low antioxidant activity (GSH) and by histological changes as well. Many studies have reported structural changes in the kidney $[5,25,26]$. The level of kidney MDA in the CP-treated group was significantly higher compared with their levels in the controls. Increased MDA (36\%) levels indicated that lipid peroxidation, mediated by ROS, was an important contributing factor in the development of CP-mediated tissue damage $(p<0.05)$. However, pretreatment with SLM significantly prevented CP-induced lipid peroxidation in the kidney tissues, implicating an antioxidant effect from this trace element. This was probably due to less damage having occurred from oxygen-free radicals.

GSH is the most important molecule for maintaining cell integrity and participation in cell metabolism [27]. The significant reduction in GSH levels promoted by CP represents an alteration in the cellular redox state, suggesting that the cells could be more sensitive to ROS. This leads to a reduction in effectiveness of the antioxidant enzyme defense system [28]. In this study, GSH levels in the kidney tissues of rats treated with $\mathrm{CP}$ were lower $(28 \%)$ than the control groups $(p<0.05)$. On the other hand, an increase in GSH levels in the kidney tissues indicated that pretreatment with SLM caused the increase as a response to oxidative stress.

Se is recognized to have a capacity for conferring tolerance to the toxic manifestations of various heavy metal exposures, including cadmium, mercury, lead, and arsenic [29, 30] in addition to role as an anticancer agent [31]. Moreover, Se has protective effects against mercury toxicity in rat kidney and Se also used to diminish the toxic effects of the cadmium on the antioxidant enzyme system, which in turn affects the membranes structures such as 

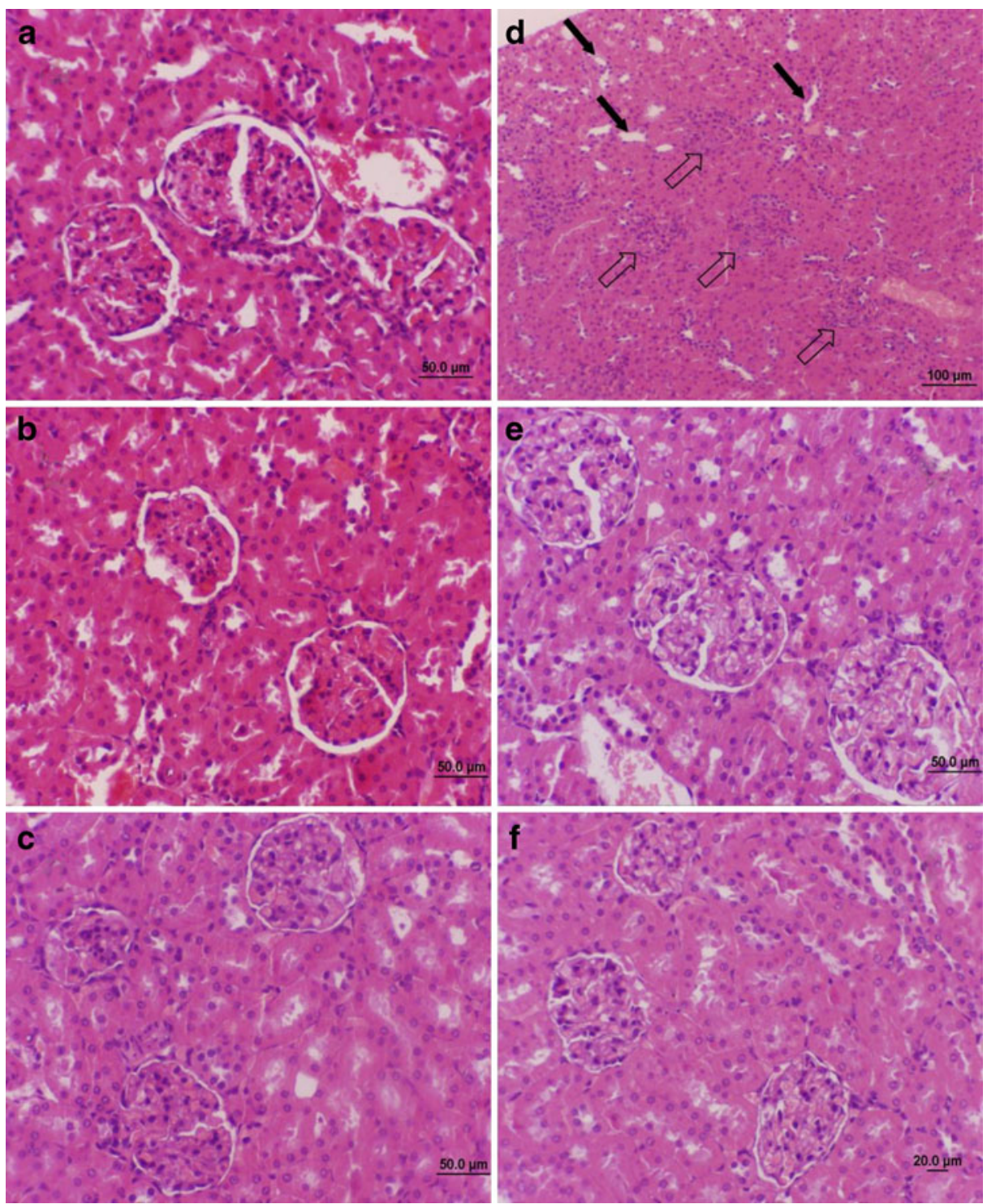

Fig. 3 Micrographs of kidney cortexes of the rats from a control, b 0.5 SLM, and $\mathbf{c} 1$ SLM groups showing normal histology; d CP group showing degenerated tubules (black arrows) and narrowing of Bowman's capsule spaces (white arrows); $\mathbf{e} \mathrm{CP}+0.5 \mathrm{SLM}$ and $\mathbf{f} \mathrm{CP}+1$ SLM showing almost normal architecture. All sections were stained with $\mathrm{H} \& \mathrm{E}$

mitochondria and endoplasmic reticulum. On the other hand, Se deficiency reducing GSHPx activity has been reported in the diet of glomerular disease and in the diet of tubular epithelium in normal rats [32]. Concurrent or prior injections of Se were found to protect against many of the acute effects of cadmium, e.g., testicular necrosis, placental hemorrhage, teratogenecity, and damage to the lactating mammary glands [31-34].

These results correlated well with the microscopical results from the kidneys, which revealed tubular necrosis in the renal cortex. The kidneys of the control and SLM groups 
showed normal histology. However, rats given CP had a moderately severe glomerular congestion and degeneration and dilatation in Bowman's space and in the collective tubules in the kidney sections. On the other hand, the tubule cells from rats in the CP+SLM groups were nearly normal in histological architecture, except for a minor desquamation of the kidney epithelial cells. Similar findings were also reported by Tripathi and Jena [35], and Babu et al. [25], demonstrating the structural changes in the kidney tissues of CP-treated animals and its healing by different agents.

In this study, we have shown that experimental CP administration caused an increase in lipid peroxidation in rats, which we believe is a result of the oxidative stress caused by CP, and SLM can act as a protective pharmacological agent or decrease the side effects of CPinduced kidney toxicity.

\section{References}

1. Dollery C (1999) Cyclophosphamide. Therapeutic drugs. Churchill Livingstone, Edinburg, pp 349-353

2. Kopecna L (2001) Late effects of anticancer therapy on kidney function in children with acute lymphoblastic leukemia. Bratisl Lek Listy 102:357-360

3. Okamura T, Garland EM, Taylor RJ, Johansson SL, Cohen SM (1992) The effect of cyclophosphamide administration on the kidney of the rat. Toxicol Lett 63:261-276

4. Gustafsson LL, Eriksson L, Dahl S, Eleborg L (1996) Cyclophosphamide induced acute liver failure requiring transplantation in a patient with genetically deficient debrisoquine metabolism: a causal relationship? J Int Med 240:311-314

5. Rossi R, Godde A, Kleinebrand A, Riepenhausen M, Boos J, Ritter J (1994) Unilateral nephrectomy and cisplatin as risk factor of ifosfamide-induced nephrotoxicity: analysis of 120 patients. J Clin Oncol 12:159-165

6. Sugumar E, Kanakasabapathy I, Abraham P (2007) Normal plasma creatinine level despite histological evidence of damage and increased oxidative stress in the kidneys of cyclophosphamide treated rats. Clin Chim Acta 376:244-245

7. Abraham P, Rabi S (2009) Nitrosative stress, protein tyrosine nitration, PARP activation and NAD depletion in the kidneys of rats after single dose of cyclophosphamide. Clin Exp Nephrol 13:281-287. doi:10.1007/s10157-009-0160-z

8. Kern JC, Kehrer JP (2002) Acrolein-induced cell death: a caspase-influenced decision between apoptosis and oncosis/necrosis. Chem Biol Interact 139:79-95

9. Arumugam N, Sivakumar V, Thanislass J, Devaraj H (1997) Effects of acrolein on rat liver antioxidant defense system. Indian J Exp Biol 35:1373-1374

10. Mythili Y, Sudharsan PT, Selvakumar E, Varalakshmi P (2004) Protective effect of dl-a-lipoic acid on cyclophosphamide induced oxidative cardiac injury. Chem Biol Interact 151:13-19

11. Kawanishi M, Matsuda T, Nakayama A, Takebe H, Matsui S, Yagi T (1998) Molecular analysis of mutations induced by acrolein in human fibroblast cells using supf shuttle vector plasmids. Mut Res Gen Toxicol Environ Mutagen 417:65-73

12. Fouladi M, Stempak D, Gammon J (2001) Phase I trial of a twice-daily regimen of amifostine with ifosfamide, carboplatin and etoposide chemotherapy in children with refractory carcinoma. Cancer 92:914-923

13. Schrauzer GN (2003) The nutritional significance, metabolism, and toxicology of selenomethionine. Adv Food Nutr Res 47:73-112

14. Flohe L, Gunzler WA, Loschen G (1979) The glutathione peroxidase reaction: a key to understand the selenium requirement of mammals. Trace metals in health and disease. Raven, New York, pp 263-286

15. Bauer G, Wendel A (1980) The activity of the peroxide-metabolizing system in human colon carcinoma. J Cancer Res Clin Oncol 97:267-273

16. Cao S, Durrani FA, Rustum YM (2004) Selective modulation of the therapeutic efficacy of anticancer drugs by selenium containing compounds against human tumor xenografts. Clin Cancer Res 10:25612569

17. Ayhanci A, Uyar R, Aral E, Kabadere S, Appak S (2008) Protective effect of zinc on cyclophosphamideinduced hematoxicity and urotoxicity. Biol Trace Elem Res 126:186-193 
18. Mohan IK, Khan M, Shobha JC, Naidu MU, Prayag A, Kuppusamy P (2006) Protection against cisplatin-induced nephrotoxicity by Spirulina in rats. Cancer Chemother Pharmacol 586:802-808

19. Ohkawa H, Ohishi N, Yagi K (1979) Assay for lipid peroxides in animal tissues by thiobarbituric acid reaction. Anal Biochem 95:351-358

20. Levine LA, Richie JP (1989) Urological complications of cyclophosphamide. J Urol 141:1063-1069

21. Ayhanci A, Yaman S, Sahinturk V, Uyar R, Bayramoglu G, Senturk H, Altuner Y, Appak S, Gunes S (2009) Protective effect of seleno-L-methionine on cyclophosphamide-induced urinary bladder toxicity in rats. Biol Trace Elem Res. doi:10.1007/s 12011-009-8458-y

22. Philips FS, Sternberg SS, Cronin AP, Vidal PM (1961) Cyclophosphamide and urinary bladder toxicity. Cancer Res 21:1577-1589

23. Levine S, Sowinski R (1974) Cyclophosphamide-induced cerebral and visceral lesions in rats. Arch Pathol 98:177-182

24. Hsu HC, Tsai HM (1982) Cyclophosphamide-induced glomerular injury in newborn mice. Lab Invest 47:281-285

25. Senthilkumar S, Devaki T, Manohar BM, Babu MS (2006) Effect of squalene on cyclophosphamideinduced toxicity. Clin Chim Acta 364:335-342

26. Cayir K, Karadeniz A, Yildirim A, Kalkan Y, Karakoc A, Keles M, Tekin SB (2009) Protective effect of L-carnitine against cisplatin-induced liver and kidney oxidant injury in rats. Cent Eur J Med 4(2):184 191

27. Lu Y, Cederbaum A (2007) The mode of cisplatin-induced cell death in CYP2E1-overexpressing HepG2 cells: modulation by ERK, ROS, glutathione, and thioredoxin. Free Radic Biol Med 43:1061-1075

28. Nannelli A, Messina A, Marini S, Trasciatti S, Longo V, Gervasi PG (2007) Effects of the anticancer dehydrotarplatin on cytochrome P450 and antioxidant enzymes in male rat tissues. Arch Toxicol 81:479487

29. Whanger PD (1981) Selenium and heavy metal toxicity. In: Spallholz JE, Martin JL, Ganther HE (eds) Selenium in biology and medicine. AVI, Westport, pp 230-255

30. Diplock AT, Watkins WJ, Heurson M (1986) Selenium and heavy metals. Ann Clin Res 18:55-60

31. Ip C (1986) Selenium and experimental cancer. Ann Clin Res 18:22-29

32. Jamba L, Nehru B, Bansal MP (1997) Selenium supplementation during cadmium exposure: changes in antioxidant enzymes and the ultrastructure of the kidney. The Journal of Trace Elements in Experimental Medicine 10:233-242

33. Gray KJ, Engelmann UH, Fishman IJ (1986) Evaluation of misoprostol cytoprotection of the bladder with cyclophosphamide (cytoxan) therapy. J Urol 133:497-500

34. Furst A (2002) Can nutrition affect chemical toxicity? Int J Toxicol 21:419-424

35. Tripathi DN, Jena GB (2008) Ebselen attenuates cyclophosphamide-induced oxidative stress and DNA damage in mice. Free Radic Res 42(11):966-977 